Solar flares in the form of abnormally bright patches on the sun's surface were first noticed in 1859 but were thought to be extremely rare until in the early 1930s the spectrohelioscope showed them to be fairly frequent. The final surprise came in 1942 with the discovery that they bring not only light from the sun but a high-speed hail of particles of matter, mainly protons, capable of damaging living tissues in outer space or even in the high atmosphere. J. H. Reid, ${ }^{2}$ of Houston Aerospace Systems, listed 16 "major" flares detected between 1942 and 1967. They were not evenly spread over the years but were dependent on the "solar cycle" - a period averaging about 11 years, during which the number of sunspots increases to a maximum and then decreases to a minimum. At present we are at the end of a safe period and must expect flares again.

The International Commission for Radiation Protection gives 0.5 rem per year as the maximum permissible radiation dose. According to $\mathrm{Reid}^{2}$ a supersonic passenger exposed to every major flare during a complete solar cycle would accumulate $4.4 \mathrm{rem}$ in the 11 years, an average of 0.4 rem per year. But the dose is much higher for a pilot, flying for 40 hours a month at $75,000 \mathrm{ft}(22,900 \mathrm{~m})$, especially if he flies over the polar regions. He will in addition receive cosmic radiation from the rest of the universe as well as secondary radiation caused by energetic particles hitting the cabin walls, and the total adds up to an average of 1.6 rem per year if he takes no avoiding action by diving. But the most dangerous flares can produce at their onset a high radiation dose.

How much time would be available for diving down to a safer altitude, such as $40,000 \mathrm{ft}(12,200 \mathrm{~m})$, where atmospheric shielding is $200 \mathrm{~g} / \mathrm{cm}^{2}$ ? During the 16 major flares listed by Reid $^{2}$ the times taken for the first and most energetic particles to travel from sun to earth vary from 6 hours 40 minutes for the flare of 3 September 1960 to 26 minutes for that of 23 February 1956 and 25 minutes for that of 4 May 1960. Diving at $30^{\circ}$ to the horizontal and going at twice the speed of sound, an aircraft would lose height at just the speed of sound, and drop from 80,000 to $40,000 \mathrm{ft}$ $(24,400$ to $12,200 \mathrm{~m})$ in 36 seconds. In practice, initiation of the dive would have to be gradual, or everything in the cabin would acquire negative weight, and even passengers strapped in and holding on to their glasses would see their drinks rise before them and splash on to the roof. There would be plenty of time to get down provided the onset of the flare on the sun can be observed. But can it? Much has been learned in the past two years, Molton ${ }^{1}$ states, about the observable conditions which favour flare formation, so that prediction may be possible.

Astronauts take longer than aircraft to get down, even from earth orbit, and on a moon journey may have to suffer a flare which lasts for 8 hours or so. However, the earliest and most dangerous particles come almost in a straight line from the sun, so the cabin contents can be piled against the thickest part of the wall as partial shielding. Later particles have time to be diverted by the magnetic field between earth and sun and may hit the ship from all directions. It would be impractical to take up an enormous weight of shielding against such a rare event. So Molton ${ }^{1}$ mentions several electrical and magnetic methods of deflecting the radiation from a spacecraft. A further possibility is biological shielding, this last being achieved by a layer of Micrococcus radiodurans. This micro-organism can tolerate 400,000 rem of radiation without appreciable mortality, which it does by quick repair of radiation damage by means of special enzymes. Travellers to Mars should be all right. E. Opik ${ }^{3}$ assures them that "little or no corpuscular radiation from these disturbances should reach Mars or beyond."

1 Molton, P. M., Spaceflight, 1971, 13, 220.

Reid, J. H., Irish Astronomical fournal, 1969, 9, 69.

3 Ôpik, E., Irish Astronomical fournal, 1963, 6, 29.

\section{Anticoagulant Interactions}

Interactions between oral anticoagulants of the coumarininanedione groups and other drugs are common. They lead to an upset in the normal balance of the clotting systems dependent on vitamin $\mathbf{K}$. The result may be serious haemorrhage, occurring either when a drug is given which increases the anticoagulant action or when a drug which reduces this action is stopped.

A wide variety of drugs, including many tranquillizers and antidepressants, barbiturates, and other sedatives such as glutethimide, diphenhydramine, and meprobamate stimulate increased synthesis of the liver microsomal enzymes ("enzyme induction"). The latter are responsible for metabolizing and inactivating many drugs, including most oral anticoagulants. When a patient is given an enzyme-inducing agent the effect of the anticoagulant is reduced. Conversely, when the prothrombin time is being controlled in the therapeutic range in a patient who is taking such an agent, the anticoagulant effect increases when it is stopped. Serious haemorrhage may occur some days later unless the dose of the anticoagulant is reduced. A. Breckenridge and his colleagues, ${ }^{1}$ studying dichloralphenazone (a complex of antipyrine and chloral hydrate), have recently found that its enzyme-inducing effects were due to antipyrine. They also confirmed an earlier report ${ }^{2}$ that chloral displaced warfarin from its binding sites on the plasma proteins. In both studies the patients' plasma warfarin levels fell, indicating that the free drug, while available for its biological effect, was also available for enzymatic hydroxylation. E. M. Sellers and $\mathrm{J}$. Koch-Weser found that the anticoagulant effect of warfarin was enhanced when chloral was given, but Breckenridge and his colleagues did not confirm this. Conversely, there has been one report of fatal haemorrhage in a patient whom the prothrombin time rose sharply when chloral hydrate was stopped-suggesting that chloral had reduced the anticoagulant effect. ${ }^{3}$

Clearly, therefore, the interplay between anticoagulant displacement and metabolism cannot be predicted in the individual patient when chloral is given. However, these results do show that both chloral hydrate and dichloralphenazone are unsuitable sedatives for patients on oral anticoagulants. But, though chlordiazepoxide is an enzyme inducer in the rat, ${ }^{4}$ it does not seem to affect warfarin requirements in man. ${ }^{5}$ Nitrazepam is also thought to be a safe sedative during anticoagulant treatment.

A high proportion of a dose of oral anticoagulants becomes bound to plasma protein after absorption. This fraction may be displaced by other highly protein-bound acidic drugs including phenylbutazone, oxyphenbutazone, salicylates, indomethacin, mefenamic acid, probenecid, nalidixic acid, sulphonamides, clofibrate, diazoxide, and ethacrynic acid. ${ }^{6-9}$ Serious and fatal haemorrhage has followed the use of some of these drugs in patients taking anticoagulants, suggesting that the drugs have a potentiating effect. However, displacement may not be the only mechanism responsible; phenylbutazone and other pyrazolones may inhibit the enzyme hydroxylating warfarin ${ }^{10}$; and salicylates—some of which also 
inhibit microsomal enzymes ${ }^{11}$ — have an anticoagulant effect similar to that of warfarin itself. Clofibrate may increase the affinity of the receptor for warfarin in the liver, ${ }^{12}$ and may also have an indirect effect by lowering serum cholesterol. ${ }^{13}$

The salicylate interaction is possibly the commonest and, because salicylates are freely available in many proprietary preparations, it may also be the least preventable. Clearly, patients must have the risks of self-medication very carefully explained. Unfortunately paracetamol is not an ideal substitute for salicylates, as it also has a slight potentiating effect on warfarin by an unknown mechanism. ${ }^{14}$

Some other miscellaneous interactions should also be mentioned. Quinidine has a direct, and additive, effect on vitamin-K-dependent clotting systems. ${ }^{15}$ Many drugs-including methyl phenidate, ${ }^{16}$ phenyramidol, ${ }^{17}$ disulfiram, ${ }^{18}$ and some monoamine oxidase inhibitors ${ }^{19}$-inhibit the metabolism of warfarin. Broad-spectrum antibiotics ${ }^{20}$ or liquid paraffin $^{21}$ may reduce the absorption of vitamin $\mathrm{K}$ and thus potentiate the oral anticoagulants. Glucagon, in high dosage as used in heart failure, increases the effects of warfarin by an unknown mechanism. ${ }^{22}$ Steroid drugs have complex actions. Many-including oestrogens, androgens, progestogens, anabolic agents, and glucocorticoids-compete with warfarin for the same system of hydroxylating enzymes. ${ }^{23}$ But most of these stimulate synthesis of those enzymes. ${ }^{24}$ The anabolic agents are known to reduce warfarin requirements, ${ }^{12} 25$ but they may do this by increasing the affinity of the receptor that warfarin occupies in the liver.

Alcohol has been reported as increasing anticoagulant requirements by acting as an enzyme-inducing agent. ${ }^{26}$ Nevertheless, it may also potentiate anticoagulant effects, ${ }^{27}$ possibly because cholestasis leads to malabsorption of vitamin $\mathrm{K}$ or because retained bile salts inhibit microsomal enzymes.

When a patient on an oral hypoglycaemic drug or an epileptic on phenytoin requires anticoagulant treatment it is important to remember that the coumarins inhibit the metabolism of tolbutamide, ${ }^{28}$ chlorpropamide, ${ }^{29}$ and phenytoin, ${ }^{30}$ and may cause hypoglycaemia or phenytoin intoxication. Phenindione does not have this effect and, if no adverse reaction occurs in the individual patient, is probably a more satisfactory anticoagulant when these agents have to be used.

Patients on oral anticoagulants are at considerable risk and should be regarded as unsuitable for long-term outpatient treatment if they are unreliable and repeatedly miss appointments at the anticoagulant clinic, or if they are prone to selfmedication or to bouts of heavy drinking. Doctors, who cannot possibly remember all the drugs known to cause interaction, or predict what new drugs are likely to do so, must carefully consider the possible consequences of any change in treatment, and particularly beware of proprietary preparations with which they are unfamiliar and which may contain a barbiturate or salicylate. Though anticoagulants are now used less in some common diseases, many patients remain who take them long term, and probably considerable morbidity and some mortality still results from preventable or predictable drug interaction.

${ }^{1}$ Breckenridge, A., Orme, M. L'E., Thorgeirsson, S., Davies, D. S., and Brooks, R. V., Clinical Science, 1971, 40, 351.

Sellers, E. M., and Koch-Weser, J., New England fournal of Medicine, $1970,283,827$

3 Cucinell, S. A., Odessky, L., Weiss, M., and Dayton, P. G., fournal of the American Medical Association, 1966, 197, 366.

- Hoogland, D. R., Miya, T. S., and Bousquet, W. F., Toxicology and Applied Pharmacology, 1966, 9, 116.

Robinson, D. S., and Sylvester, D., Annals of Internal Medicine, 1970, 72,
- Aggeler, P. M., O'Reilly, R. A., Leong, L., and Kowitz, P. E., New England fournal of Medicine, 1967, 276, 496.

Prescott, L. F., Lancet, 1969, 2, 1239.

${ }^{8}$ Sellers, E. M., and Koch-Weser, J., Clinical Pharmacology and Therapeutics, 1970, 11, 524 .

Solomon, H. M., and Schrogie, J. J., Biochemical Pharmacology, 1967, 16, 1219.

10 Weiner, M., Siddiqui, A. A., Bostanci, N., Dayton, P. G., Federation Proceedings, 1965, 24, 153.

11 Rogers, L., Alcantara, G. A., and Fouts, J. R., Fournal of Pharmacology and Experimental Therapeutics, 1963, 142, 242 .

12 Schrogie, J. J., and Solomon, H. M., Clinical Pharmacology and Therapeutics, $1967,8,70$.

13 Pyörälä, K. Nikkilä, E. A., Vuopio, P., and Myllylä, G., Acta Medica Scandinavica, 1968, 183, 437.

14 Anlitz, A. M., Mead, J. A., and Tolentino, M. A., Current Therapeutic Research, 1968, 10,501.

15 Koch-Weser, J., Annals of Internal Medicine, 1968, 68, 511.

${ }_{16}$ Garretson, L. K., Perel, J. M., and Dayton, P. G., Fournal of the American arretson, L. K., Perel, J. M., and Dayton

17 Solomon, H. M., Schrogie, J. J., fournal of Pharmacology and Experimental Therapeutics, 1966, 154, 660.

${ }_{18}$ Rothstein, E., Fournal of the American Medical Association, 1968, 206, 1574.

${ }^{19}$ Reber, K., and Studer, A., Thrombosis et diathesis haemorrhagica, 1965, $14,83$.

${ }^{20}$ Coon, W. W., and Willis, P. W., Clinical Pharmacology and Therapeutics, $1970,11,312$.

${ }^{21}$ Loeliger, E. A., in Side Effects of Drugs, Vol. 6, p. 466. Ed. Meyler and A. Herxheimer, Excerpta Medica Foundation, Amsterdam, 1968.

22 Koch-Weser, J., Annals of Internal Medicine, 1970, 72, 331.

${ }_{23}$ Tephly, T. R., and Mannering, G. J., Pharmacologist, 1964, 6, 186.

${ }_{24}$ Conney, A. H., Pharmacological Reviews, 1967, 19, 317.

${ }_{25}$ Pyörälä, K., H., Pharmacological Reviews, 1967, 19,

${ }_{26}^{25}$ Pyörälä, K., and Kekki, M., Lancet, 1963, 2, 360. 690.

${ }_{27}$ Reidler, G., Thrombosis et diathesis haemorrhagica, 1966, 16, 613.

27 Reidler, G., Thrombosis et diathesis haemorrhagica, 1966, 16, 613
${ }_{28}$ Kristensen, M., and Hansen, J. M., Diabetes, 1967, 16, 211.

${ }^{29}$ Kristensen, M., and Hansen, J. M., Acta Medica Scandinavica, 1968,

183, 83.
${ }^{30}$ Hansen, J. M., Kristensen, M., Skovsted, L., and Christensen, L. K., Lancet, 1966, 2, 265.

\section{New Antibacterial Drugs}

The proceedings of a symposium on newer antibacterial agents held at a meeting of the Association of Clinical Pathologists in September 1970 have now been published in the Fournal of Clinical Pathology. They consist in the main of three comprehensive papers reporting original observations on the antibacterial action and pharmacological behaviour of four agents which have recently been introduced, together with discussions of indications for their clinical use. Needless to say, almost all progress in the field of chemotherapy for a decade or more has resulted from synthetic modifications of existing antibiotics and not the discovery of new ones. Three of the drugs considered here are old antibiotics in new forms; the fourth, trimethoprim, differs both in being wholly synthetic and in representing a major new discovery.

Clindamycin is a subject of a contribution by I. Phillips. ${ }^{1}$ This substance is 7-chloro-7-deoxylincomycin, and very small changes in the molecule from which this antibiotic is produced have large effects on its behaviour. In an extensive series of determinations of minimum inhibitory concentrations, in which lincomycin and clindamycin were compared with erythromycin and rifampicin, Phillips confirms previous findings, mainly by workers in the United States, that clindamycin is many times more active than lincomycin against staphylococci, haemolytic streptococci, and pneumococci. It is for infections by these three organisms that this antibiotic is almost exclusively indicated, though it may be added that high activity has also been shown by other workers against Bacteroides fragilis. Add to these advantages the fact that clindamycin is much better absorbed, particularly after a meal, and it becomes clear that clindamycin should supersede lincomycin whenever this antibiotic is indicated. Its only defect is that no injectable form is available.

This paper also deals with rifampicin, which is perhaps the most spectacular of all achievements resulting from the 